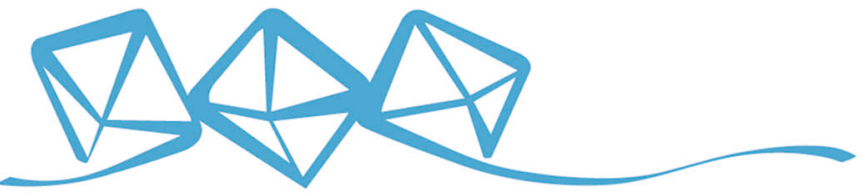 COMMUNICATIONS MATERIALS
}

ARTICLE

https://doi.org/10.1038/s43246-020-0035-0

OPEN

\section{Instantaneous fibrillation of egg white proteome with ionic liquid and macromolecular crowding}

\author{
Pankaj Bharmoria (10) 1,5, Dibyendu Mondal (1) 2,5, Matheus M. Pereira (1) 1, Márcia C. Neves (1) 1, \\ Mafalda R. Almeida (1) ${ }^{1}$, Maria C. Gomes ${ }^{1}$, João F. Mano ${ }^{1}$, Igor Bdikin ${ }^{3}$, Rute A. S. Ferreira (1) ${ }^{4}$, \\ João A. P. Coutinho (i) ${ }^{1 凶} \&$ Mara G. Freire (1) ${ }^{1 凶}$
}

The wide application of protein fibrils as functional materials has been restricted by the limited scalability of fibrillation methods, slow kinetics, and use of expensive purified proteins. Herein, inspired by the biological cooperativity of proteins in macro-molecularly crowded environments, these restrictions have been overcome. Using ionic liquid cholinium tosylate that acts as a fibrillation agent, instantaneous production of protein fibrils is shown directly from a real and low-cost matrix, i.e. egg white. The fibrillation of egg white proteome is confirmed by microscopy, whereas the fibrillation kinetics is monitored by fluorescence changes of the thioflavin $T$ dye and secondary structural transitions. Spectroscopic and molecular docking studies are used to identify the proteins involved and to appraise the molecular-level mechanisms ruling the proteins structural changes upon fibrillation. The obtained fibrils have enhanced mechanical stiffness and cytocompatibility, demonstrating their potential to act as improved enzyme supports.

\footnotetext{
${ }^{1}$ CICECO-Aveiro Institute of Materials, Department of Chemistry, University of Aveiro, Aveiro 3810-193, Portugal. ${ }^{2}$ Center for Nano and Material Science, Jain University, Jain Global Campus, Kanakapura, Ramanagaram, Bangalore 562112, India. ${ }^{3}$ TEMA, Department of Mechanical Engineering, University of Aveiro, 3810-193 Aveiro, Portugal. ${ }^{4}$ CICECO-Aveiro Institute of Materials, Department of Physics, University of Aveiro, Aveiro 3810-193, Portugal. ${ }^{5}$ These

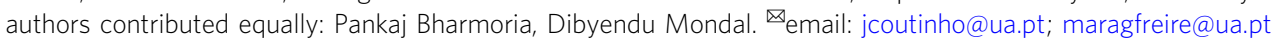


G iven the connection to amyloidogenic diseases, protein fibrillation is a hot topic of research ${ }^{1-3}$. In addition to their relevance in neurological diseases, their potential as smart and/or functional materials in nano/biotechnology has recently attracted significant interest due to their bio-based origin, high mechanical strength, and stiffness ${ }^{4-7}$. However, the low scalability of the production process, requirement of high purity and expensive proteins, and slow fibrillation kinetics, are still major hurdles to overcome when envisioning their use in large scale applications as functional biomaterials ${ }^{8}$.

Within a biological perspective, fibrils formation occurs due to multiple factors, such as environmental (heat and oxidative) stress, cellular mutations, translational errors, and aging. These factors cause partial or complete misfolding of folded intermediates due to dysfunctional chaperones (the folding regulators) ${ }^{9}$. The thermodynamically unfavorable misfolded intermediates then lead to the formation of either disordered aggregates or prefibrillar aggregates, which slowly change into stable amyloid fibrils via electrostatic, H-bonding, van der Waals, and aromatic stacking interactions $s^{9,10}$. Serpell et al. ${ }^{11}$ reported that plasma proteins that form amyloid fibrils share a common feature, namely a high $\beta$ sheet conformation, representing a clue of the proteins secondary structural requirements for fibrils formation.

The formation of amyloid fibrils has been investigated in vitro to better understand the initiation and propagation fibrillation mechanisms, applying changes on the physiological environment $\left(\mathrm{pH}\right.$, heat, and osmotic environment) of proteins ${ }^{12-14}$ and of synthesized peptides ${ }^{15-18}$. It has been concluded that the rate and efficiency of proteins fibrillation are ruled by the proteins hydrophobic-hydrophilic nature, secondary structure changes, possibility of establishing electrostatic, $\pi^{\cdots} \pi$ and hydrogenbonding interactions, among others, which can be potentiated by fibrillation agents ${ }^{12-21}$. Two major mechanisms of fibrils formation have been proposed: (i) seedling of fibrils in the form of misfolded monomeric intermediates, showing a lag phase in the kinetics curve of fibrils formation ${ }^{22}$; and (ii) formation of misfolded oligomer intermediates as seeds, in which a lag phase is absent in the kinetics curve ${ }^{23}$. Accordingly, when the goal is to induce proteins fibrillation, fibrillation agents exhibiting both polar and nonpolar domains are the best option since they can induce the formation of misfolded oligomer intermediates, while assisting in fast fibrillation by surpassing the lag phase.

Ionic liquids (ILs) ${ }^{24}$, a class of low melting temperature organic salts, if properly designed may display the desired features to promote proteins fibrillation. ILs have been used in proteins fibrillation studies ${ }^{25-27}$. Byrne et al. ${ }^{25}$ reported the fibrillation of pure lysozyme using a protic IL, where the fibrillation was induced by heating for $2 \mathrm{~h}$ at $70^{\circ} \mathrm{C}$ and keeping the mixture at room temperature for one week. Kalhor et al. ${ }^{26}$ demonstrated the inhibition of lysozyme fibrillation using the IL tetramethylguanidinium acetate, highlighting the role played by the IL carboxyl group. Contrarily to the findings of Kalhor et al. ${ }^{26}$ and Kang et al. ${ }^{27}$ demonstrated the role of the carboxyl group of ester functionalized ILs in the fibrillation of bovine serum albumin. Albeit promising results have been reported, the following features are common to all works: (i) pure proteins (lysozyme or bovine serum albumin) were used; (ii) long periods are required for the production of protein fibrils; and (iii) all processes were developed at the laboratory scale (maximum of $1-8 \mathrm{mg}$ of proteins used per batch).

An additional relevant aspect in proteins fibrillation is molecular crowding. Proteins in biological fluids are never found individually, but rather in the form of a proteome in a macromolecular crowded pool. In this complex scenario, every macromolecule affects (assists or inhibits) each other's physiological functions ${ }^{28}$. The effects of macromolecular crowding (MC) on the understanding of biochemical pathways (gene expression, protein dynamics, and folding) have faced significant advances in recent years ${ }^{29}$. For instance, MC has been harnessed for modulating systems dynamics of in vitro circuits and programmable artificial cells $^{30,31}$. MC has been studied within the framework of proteins fibrillation as well, but these studies are limited either to single proteins at high concentration and/or use of some polymers as crowding media ${ }^{32-34}$.

Inspired by the proteins in vivo cooperativity and $\mathrm{MC}$, we mimicked these conditions to prepare protein fibrils from protein-rich pools. Herein, we explored the production of protein fibrils directly from chicken egg white (EW), selected as a lowcost MC media (rich in different proteins at concentrations $>100 \mathrm{mg} / \mathrm{mL})^{35}$, using ILs as fibrillation agents at room temperature. The EW proteome (EWP) provides the heterogeneity of proteins required in crowded environments. Several ILs, namely cholinium methylsulfonate, cholinium chloride, benzylcholinium chloride, and cholinium tosylate ([Cho][Tos]), whose chemical structures are depicted in Fig. 1a, were screened according to their ability to establish electrostatic, $\pi^{\cdots} \pi$ and hydrogen-bonding interactions with proteins and to induce protein-protein interactions and further fibrillation.

A schematic representation of the work here developed to produce protein fibrils is displayed in Fig. 1b. The fibril formation was confirmed by UV-vis, Fourier transform-infrared (FT-IR), circular dichroism (CD), and thioflavin T fluorescence spectroscopy, and their morphology was appraised by optical, atomic force (AFM) and transmission electron (TEM) microscopy. To better understand the role of $\mathrm{MC}$ in inducing fast fibrillation we also carried out fibrillation experiments of individual proteins, namely ovalbumin, lysozyme, and their mixture. Furthermore, to gather insights on the fibrillation mechanisms at the molecular level, molecular docking studies of different ILs ions with the different proteins present in the EWP were carried out. The properties of the prepared fibrils, namely thermal stability, mechanical strength/stiffness, and functional nature were analyzed by thermogravimetry analysis (TGA), dynamic mechanical analysis (DMA), and zeta potential assays. The fibrils cytocompatibility was appraised with mouse fibroblasts (L929) cell lines. The prepared fibrils were finally investigated as support materials in biocatalysis.

\section{Results and discussion}

Preparation of protein fibrils. EW was collected from chicken eggs (purchased at a local supermarket), and diluted (1:10, v:v) in water. This solution was stirred and filtered twice to remove the insoluble lipids fraction. The aqueous filtrate $(\mathrm{pH} 8.82)$ containing the EWP was used to prepare protein fibrils. Since it is known that the denaturation of proteins promotes fibrillation due to the formation of unfolded intermediates ${ }^{36}$, the EWP was treated with $1 \mathrm{M} \mathrm{HCl}$ at $\mathrm{pH} 2.0$ to denature the proteome. Different ILs, namely cholinium methylsulfonate, cholinium chloride, benzylcholinium chloride, and cholinium tosylate ([Cho][Tos]), whose chemical structures are shown in Fig. 1a, were then investigated as fibrillating agents at low $(0.1 \mathrm{M})$ and high $(1 \mathrm{M})$ concentrations, which were added to the EWP treated with acid. Among the ILs investigated, only [Cho][Tos] showed an immediate/ instantaneous (within seconds) protein fibrillation at both concentrations. No fibrillation was observed with the remaining ILs. Although the presence of an aromatic ring in the fibrillation agent is one of the identified criteria to promote fibrillation, it is not a sufficient criterion per se. One relevant additional issue is to carry out the fibrillation at $\mathrm{pH} 2.0$, with all proteins present in their cationic state. Although benzylcholinium chloride also has an aromatic ring at the cation, charge repulsion may dominate while 
a
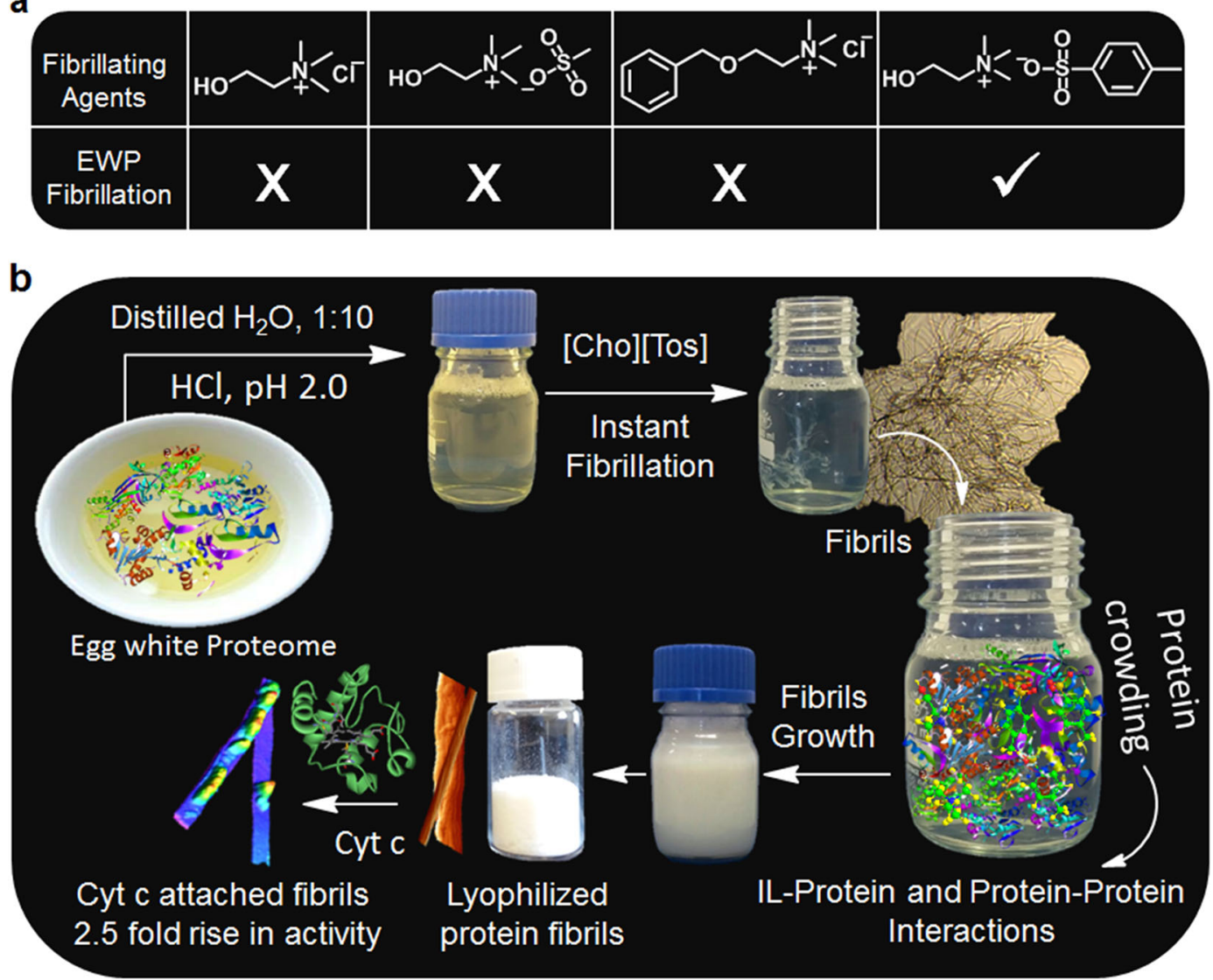

Fig. 1 Fibrillation agents and schematic representation of the work carried out. a Tested fibrillation agents to induce the fibrillation of the egg white proteome. $\mathbf{b}$ Schematic representation of the protein fibrils formation directly from egg white using the IL [Cho][Tos] as a fibrillation agent. The protein crowding effect responsible for fast fibrillation and the application of the prepared fibrils as supports for enzymes are also highlighted.

a

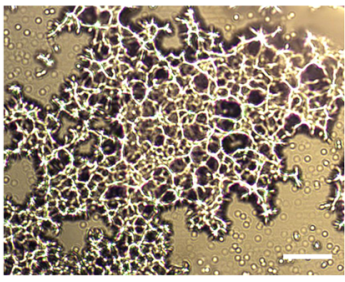

d

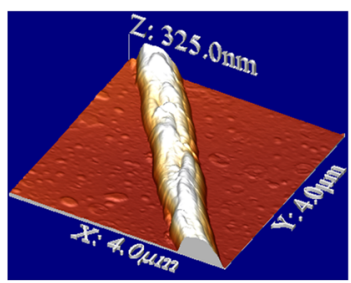

b

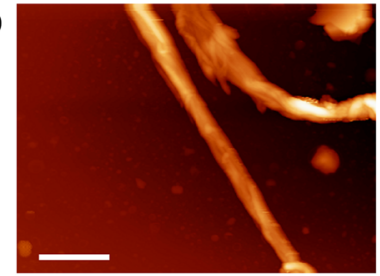

e

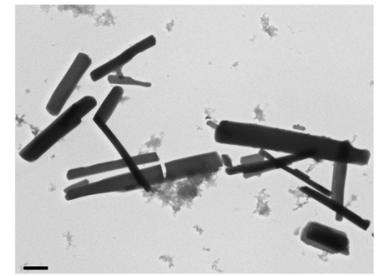

C

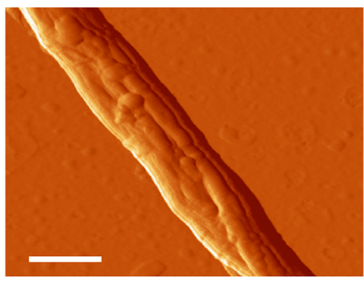

f

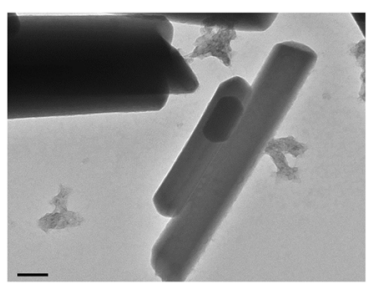

Fig. 2 Morphological characterization of the prepared fibrils. a Optical microscopy image showing instant fibrillation of egg white proteome with [Cho] [Tos] (scale bar $=10 \mu \mathrm{m}$ ). b, c 2-D AFM (scale bars $=2.8 \mu \mathrm{m}$ and $800 \mathrm{~nm}$ ) and $\mathbf{d}$ 3-D AFM images of freshly prepared fibrils showing entangles in the protein fibrils and fibril oligomers in the background. $\mathbf{d}$, e TEM images of the lyophilized protein fibrils showing one-dimensional nanorods (scale bars $=$ 500 and $100 \mathrm{~nm}$ ).

avoiding hydrophobic interactions and instant fibrillation. By being an anion, tosylate can establish electrostatic interactions with to the cationic side chains of different proteins, in addition to H-bonding, hydrophobic, and $\pi$-stacking interactions. Overall, the set of ILs investigated allow to conclude that a synergic effect and various interaction forces play a role in fibrillation. The detailed procedure to prepare the proteins fibrils is provided in the Supplementary Note 1 and Supplementary Figs. 1-3. The macroscopic visual turbidity of the solution and optical, AFM and TEM images of the prepared fibrils are shown in Fig. 2 (additional images are provided as Supplementary Fig. 2).

Highly branched fibril networks are observed at low [Cho] [Tos] concentrations, as shown by optical microscopy images given in Fig. 2a (additional images are given in Supplementary 

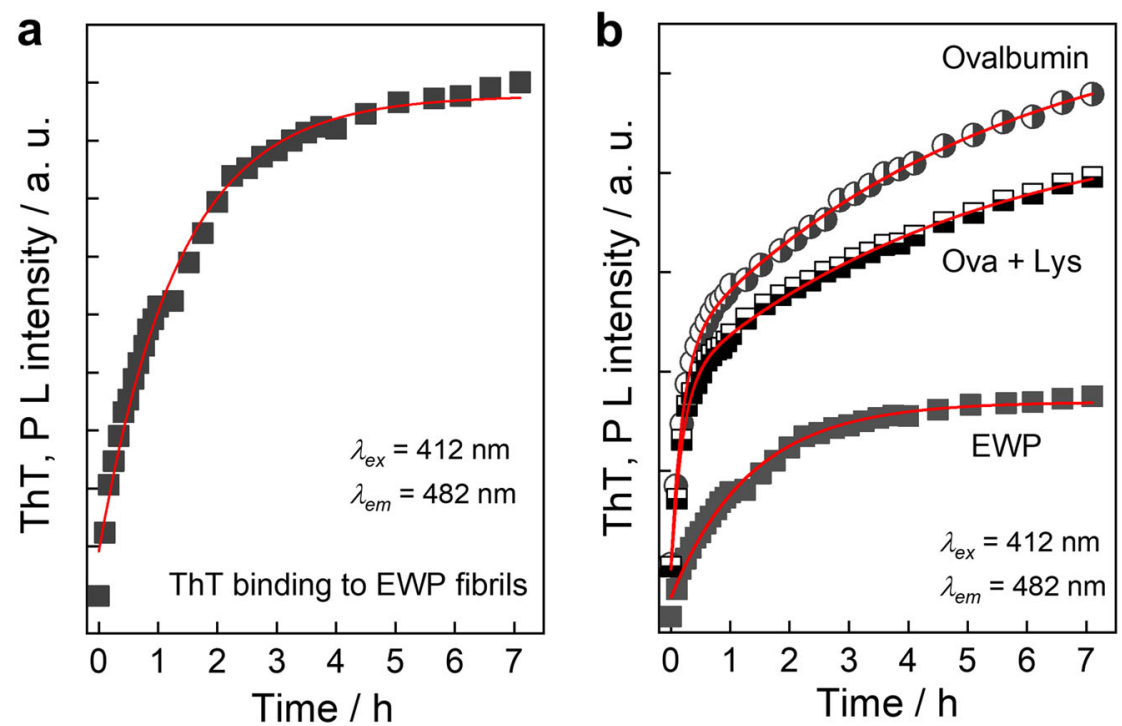

Fig. 3 Kinetics of fibrillation. a Time dependence of the photoluminescence $(P L)$ intensity of the Thioflavin $T$ dye upon binding to the cross-beta structure formed due to EWP fibrils formation and $\mathbf{b}$ comparative ThT, P L intensity vs. time plots for ThT binding to ovalbumin, ovalbumin + lysozyme, and EWP fibrils.

Fig. 2b), which turn thicker with time and at higher IL concentrations (cf. Supplementary Fig. 2c, d). AFM images show the presence of entangled protein fibrils in parallel/antiparallel arrangements (Fig. 2b-d). TEM images (Fig. 2e, f) reveal a thick bundle of fibrils with an average aspect ratio varying from 7 to 10 .

Kinetics of proteins fibrillation and evidences of cross-beta structure. The kinetics of fibrils formation was appraised by fluorescence changes of the Thioflavin $\mathrm{T}$ (ThT) dye-results depicted in Fig. 3 and Supplementary Figs. 5 and 6. The ThT dye exhibits specific binding with the cross- $\beta$ structure of proteins, leading to an enhancement in its fluorescence intensity ${ }^{37,38}$. Changes in the fluorescence intensity of ThT were recorded at different time intervals, up to $7 \mathrm{~h}$. Before fluorescence, the absorption spectra of the dye were acquired, showing that ThT absorbs at $412 \mathrm{~nm}$ with and without fibrils (results given in Supplementary Fig. 4).

At the studied concentration $(30 \mu \mathrm{M})$, ThT forms micelles in aqueous media, which specifically bind, mainly via hydrophobic interactions, along the length of the proteins cross- $\beta$ structure, leading to an increase in the fluorescence relative intensity ${ }^{37}$. When excited at $412 \mathrm{~nm}$, ThT shows emission at $482 \mathrm{~nm}$, whose emission relative intensity increases with time (Fig. 3). The increase in the fluorescence intensity with time is due to the growth of protein fibrils, in agreement with the formation of cross- $\beta$ structures 37,38 . The fluorescence spectra for samples containing protein fibrils are depicted in the Supplementary Fig. 5. To better understand the effect of MC in the EWP fibrillation, we studied the ThT binding curves with individual ovalbumin and its binary mixture with lysozyme (Fig. 3b, Supplementary Figs. 5 and 6), whose results are discussed below.

Unlike the commonly reported sigmoidal curves of protein fibrils growth using the ThT assay $22,39,40$, no lag phase was observed, supporting the claims of the instantaneous (within seconds) fibrillation visually observed. The absence of the lag phase indicates that the unfolded intermediates of the various proteins formed may be directly intercalated with [Cho][Tos] to form oligomer intermediates. The formation of oligomer intermediates of EWP is confirmed by AFM images of the fresh sample dried overnight along with fibrils (as shown in the Supplementary Fig. 7). The oligomer intermediates are usually circular in shape, and then intercalate with each other to grow into fibrils along time ${ }^{23,41}$. In the current work, the formed oligomer intermediates could be directly formed via $\mathrm{H}$-bonding and $\pi$-stacking interactions with [Cho][Tos]. The tosylate anion has an aromatic anion similar to phenylalanine, which has been reported to induce oligomers formation before the formation of fibrils ${ }^{41}$.

Secondary structural changes and proteins involved in fibrillation. To gain additional insights on the fibrils structure at the microscopic level we analyzed the changes in the secondary structure of the EWP by CD (Fig. 4a-e, Supplementary Fig. 8) (2,43 $^{4}$ and FT-IR in the amide I region $\left(1600-1700 \mathrm{~cm}^{-1}\right)$ using a deconvolution method (Fig. $4 \mathrm{f}, \mathrm{g})^{44-47}$. Since the EWP is a complex matrix, to gather evidences on the proteins involved in the fibrillation process we carried out sodium dodecylsulphate polyacrylamide gel electrophoresis (SDS-PAGE) (Fig. 4h) and UV-vis spectroscopic analysis (Supplementary Fig. 9) of the EWP before and after fibrillation. The $\mathrm{CD}$ spectrum of the acidic denatured EWP shows characteristic all- $\alpha$ secondary structure of proteins, in agreement with literature (Fig. $4 \mathrm{a})^{42}$. However, upon fibrillation, a conformational transition of all- $\alpha$ secondary structure to antiparallel $\beta$-sheet or cross- $\beta$ type occurs (Fig. 4e, Supplementary Fig. 8). This transition is a direct evidence of fibrils formation. Moreover, the time dependent CD analysis showed fast conformational transition wherein complete transition from all- $\alpha$ secondary structure to antiparallel $\beta$-sheet or cross- $\beta$ type occurs within 20 min (Fig. 4b-d).

The formation of the cross- $\beta$ structure due to fibrillation is further supported by FT-IR results (Fig. 4f, g). The spectrum of the acid denatured EWP shows seven characteristic bands, corresponding to different secondary structural contents, i.e., $\alpha$-helix $\left(1650 \mathrm{~cm}^{-1}\right)$, unordered $\left(1660 \mathrm{~cm}^{-1}\right), \beta$-sheet $\left(1634\right.$ and $\left.1680 \mathrm{~cm}^{-1}\right), \beta$-turn $\left(1667\right.$ and $\left.1696 \mathrm{~cm}^{-1}\right)$, and cross- $\beta\left(1626 \mathrm{~cm}^{-1}\right)^{45}$. Upon addition of [Cho][Tos], there is a shift in the absorption bands at 1626 to $1620 \mathrm{~cm}^{-1}$ and increase in the peak area, and at 1650 ( $\alpha$-helix) to $1647 \mathrm{~cm}^{-1}$, thus confirming the formation of cross- $\beta$ structures leading to fibrillation ${ }^{46,47}$.

The participation of various proteins of the EWP in fibrils formation was appraised by SDS-PAGE and UV-vis spectroscopy. The SDS-PAGE results (Fig. 4h) reveal the participation of 

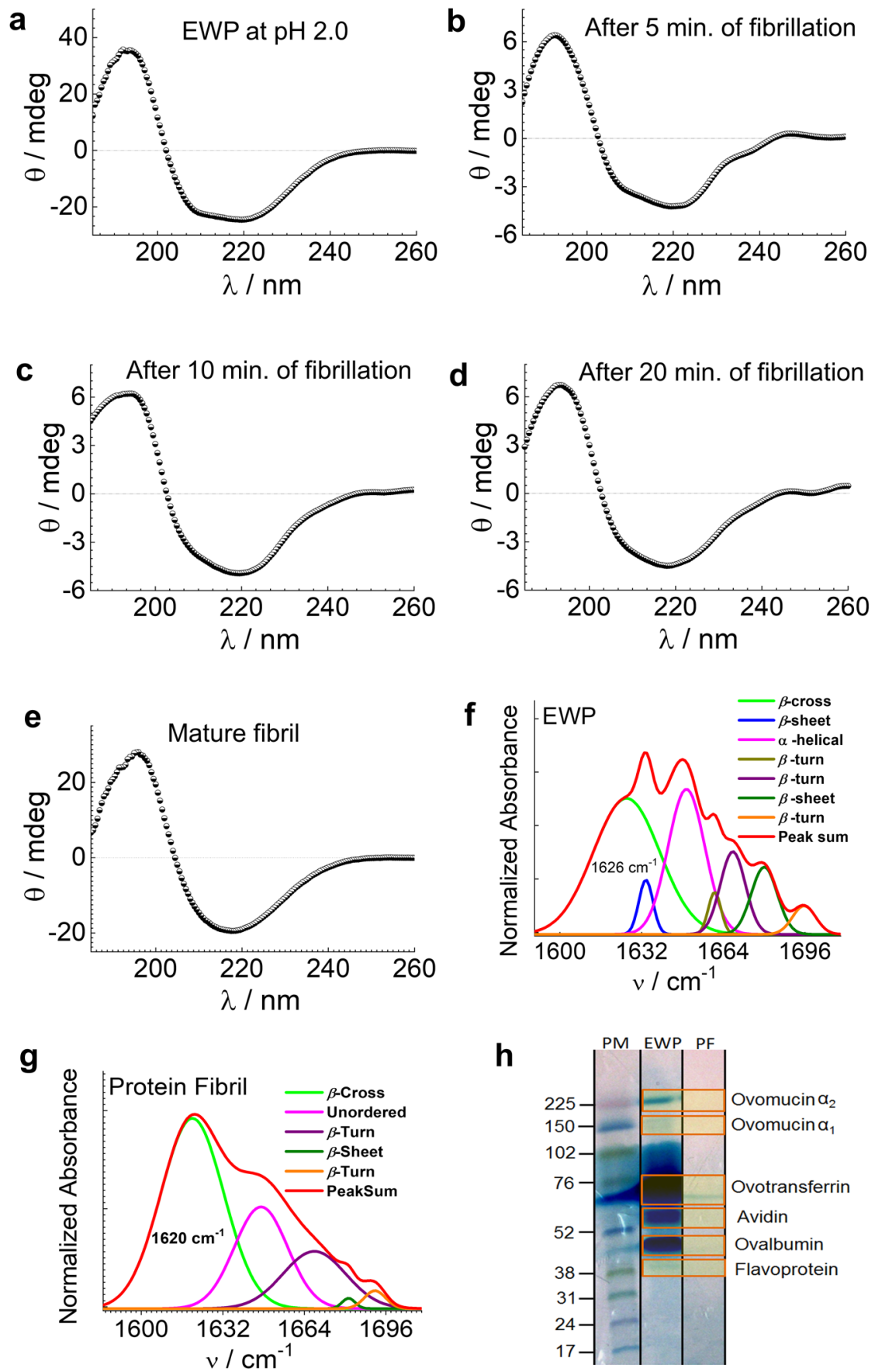

Fig. 4 Proteins secondary structural changes and proteins involved in fibrillation. a Circular dichroism (CD) spectrum of EWP showing all- $\alpha$ conformation. b-e CD spectrum showing transition in all- $\alpha$ conformation of EWP upon fibrillation at different time interval to antiparallel- $\beta$ or cross- $\beta$ in fibrils. $\mathbf{f}, \mathbf{g}$ Deconvoluted FT-IR spectra showing changes in secondary structure of EWP $\mathbf{f}$ before fibrillation and $\mathbf{g}$ after fibrillation. $\mathbf{h}$ SDS-PAGE results of the protein markers (PM), egg white proteome (EWP) solution, and protein fibrils (PF) solution.

the most abundant proteins, namely ovomucin, ovotransferrin, ovalbumin, avidin, and flavoprotein, in fibrils formation. The formation of fibrils was also confirmed by the disappearance of UV-vis absorption bands corresponding to flavoprotein (at $365 \mathrm{~nm}$ ) and ovotransferrin (at $450 \mathrm{~nm}$ ) and blue shifting of the bands at $280 \mathrm{~nm}$ (shown in the Supplementary Fig. 9). The blue shift at $280 \mathrm{~nm}$ (corresponding to the tryptophan (Trp), tyrosine (Tyr), and phenylalanine (Phe) aromatic amino acids) is accompanied by its pentafurcation to $280 \mathrm{~nm}$ (Trp), $225 \mathrm{~nm}$, $261 \mathrm{~nm}$ (Phe), $267 \mathrm{~nm}$, and $271 \mathrm{~nm}$ (Tyr). The possible association of the tosylate aromatic anion with the aromatic amino acid residues at the proteins surface via hydrophobic or $\pi$-stacking interactions during fibrillation thus contrasted their respective vibronic bands. This observation is supported by previously reported hydrophobic and $\pi$-stacking interactions of Phe and Tyr residues as playing a key role in fibrillation ${ }^{19,41}$. The relevant role of Phe23 (owing to its conformational flexibility) in fibrillation by inducing the association between sheets to cement macromolecular assemblies through interactions with other aliphatic residues has been demonstrated by simulation ${ }^{21}$ and experimental $^{41}$ studies. The relevance of $\pi$-stacking interactions in proteins fibrillation occurring with cholinium tosylate is 
Table 1 Interaction energies of the IL ions with the proteins present in egg white.

\begin{tabular}{|c|c|c|c|c|c|}
\hline Ion & Ovalbumin & Ovotransferrin & Lysozyme & Ovomucoid & Flavoprotein \\
\hline [Cho] $^{+}$ & -2.1 & -3.0 & -2.2 & -2.6 & -2.5 \\
\hline & -0.8 & -0.9 & -0.6 & -0.8 & -0.8 \\
\hline$[\text { Tos }]^{-}$ & -3.7 & -4.8 & -3.8 & -4.0 & -4.5 \\
\hline$\left[\mathrm{CH}_{3} \mathrm{SO}_{3}\right]^{-}$ & -2.1 & -2.5 & -2.4 & -2.1 & -2.6 \\
\hline
\end{tabular}

additionally confirmed by the results obtained with the remaining cholinium-based ILs that do no comprise an aromatic anion and do no induce proteins fibrillation.

To address the role of individual ions or of the IL as a specific cation-anion pair on fibrillation, studies with $\mathrm{Na}$ [Tos] and [Cho] $\mathrm{Cl}$ were additionally carried out. Aqueous solutions of $1 \mathrm{M}$ of [Cho]Cl, Na[Tos], [Cho]Cl + Na[Tos] (1:1, mol:mol) and [Cho] [Tos] were added to the EWP at $\mathrm{pH}$ 2.0. The results obtained are shown in the Supplementary Fig. 10. No fibrillation was observed with [Cho]Cl, even after $24 \mathrm{~h}$ (Supplementary Fig. 11). Nevertheless, instant fibrillation was observed with $\mathrm{Na}[\mathrm{Tos}]$, demonstrating the major role played by the tosylate anion that bears sites for $\mathrm{H}$-bonding and $\pi$-stacking interactions to drive fibrillation. The relevance of $\pi$-stacking interactions is also reflected in the UV-vis spectra, with a maximum increase in the absorbance with the pentafurcation of the respective band. It should be however remarked that the fibrils formed with [Cho] [Tos] are thinner than those obtained with $\mathrm{Na}$ [Tos]. On the other hand, no instant fibrillation was observed with $[\mathrm{Cho}] \mathrm{Cl}+\mathrm{Na}$ [Tos] mixtures; it only occurs when higher amounts of salts are added. This suggests a relevant role also played by the cholinium cation, probably by balancing the strength of the interactions of the tosylate anion with the proteins. Overall, [Cho][Tos] induces the fibrillation of the EWP via the secondary structural transition of proteins to the cross $-\beta$ structure, mainly due to H-bonding and $\pi$-stacking interactions established with amino acids, while assisting side chain interactions between different proteins as discussed below. Once nucleated the fibril seeds, propagation occurs like prion mechanism along with time ${ }^{48}$.

Molecular docking and spectroscopic studies. For a better understanding of the protein's fibrillation mechanism, we investigated the protein-protein and IL-protein interactions by molecular docking. The proteins studied correspond to ovalbumin, ovotransferrin, flavoprotein, ovomucoid, and lysozyme, and were selected based on the previous evidences of their participation in fibrillation. Details of the computational procedure are given in Supplementary Note 2. In addition to [Cho][Tos], the interactions of EWP with [BzCho][Cl] (IL with an aromatic ring) and [Cho] $\left[\mathrm{CH}_{3} \mathrm{SO}_{3}\right]$ (a nonaromatic IL) that do not induce instant fibrillation were investigated by molecular docking. The interaction energies of the IL ions with the various proteins are given in Table 1. Additional data (docking potential) are provided in Supplementary Tables 1-5. The interaction energies of the IL ions with the different proteins follow a similar trend, decreasing according to the following rank: $[\mathrm{Tos}]^{-}>[\mathrm{BzCho}]^{+}>[\mathrm{Cho}]^{+} \sim\left[\mathrm{CH}_{3} \mathrm{SO}_{3}\right]^{-}>\mathrm{Cl}^{-}$. These results are in agreement with experimental findings, where IL aromatic ions establish stronger interactions with proteins, being favorable for proteins fibrillation, and where the $[\mathrm{Tos}]^{-}$anion plays a major role.

Docking studies (Fig. 5a-c, Supplementary Figs. 12-35) reveal that hydrogen bonding and hydrophobic interactions are the major interactions occurring between the tosylate anion and amino acids. Preferential hydrogen-bonding occurs with alanine, astanine, tyrosine, histidine, lysine, glycine, and serine, whereas preferential hydrophobic interactions occur with leucine, phenylalanine, valine, histidine, arginine, alanine, and tyrosine. Accordingly, the success of [Cho][Tos] in fibrillation is due to strong hydrogen-bonding and hydrophobic interactions established with the amino acids proteins. This trend is further supported by the fact that the $[\mathrm{BzCh}]^{+}$and $\left[\mathrm{CH}_{3} \mathrm{SO}_{3}\right]^{-}$ions, which interact with amino acids mainly via electrostatic interactions (Supplementary Tables S5), are not able to induce the EWP fibrillation. [Tos] ${ }^{-}$also exhibits $\pi$-stacking interactions with Phe645 of ovotransferrin, being these interactions additionally favorable to promote fast fibrillation.

The snapshots of the molecular docking of the various proteins with [Tos] ${ }^{-}$are shown in Fig. 5a-c and Supplementary Figs. 16, 21,26 , and 31 . The interaction energies of [Cho][Tos] with the different proteins decrease in the order: Ovotransferrin $>$ Flavoprotein $>$ Ovomucoid $>$ Lysozyme $>$ Ovalbumin. Among all proteins investigated, the strongest interaction occurs between $[\mathrm{Tos}]^{-}$and ovotransferrin, with an interaction energy of $-4.8 \mathrm{kcal} / \mathrm{mol}$ (Table 1 and Fig. $5 \mathrm{a}-\mathrm{c}$ ). This order of the [Cho] [Tos] interaction strength with the various proteins is related with their secondary structure, where $\beta$-sheet containing proteins are more prone to fibrillation ${ }^{11}$. Along with the [Cho][Tos] interactions, which correspond to the initiation step of the fibrillation mechanism, protein-protein interactions and the respective aggregation correspond to the key propagation step for a fast fibrillation. Evidences of $\pi$-stacking interactions established between the proteins were obtained by UV-vis assays (as discussed earlier), supporting this perspective.

Prediction of amyloid structure aggregation (PASTA ${ }^{49}$ was used to determine the aggregation free energy in protein-protein, protein disorder and secondary structure (Fig. 5d, Supplementary Tables 6-8). From the data provided in Supplementary Tables 68 , it is shown that ovalbumin has the highest self-aggregation free energy $\left(-11.07 \mathrm{kcal} \mathrm{mol}^{-1}\right)$, followed by ovotransferrin and flavoprotein. On the other hand, the ovotransfarrin-flavoprotein aggregate has the highest co-aggregation free energy $(-7.64 \mathrm{kcal}$ $\mathrm{mol}^{-1}$ ) in a crowded media. From the analysis of Fig. 5d, there is a significant increase in $\beta$-strands of most proteins. This increase in the $\beta$-strands estimated by PASTA is in agreement with the increase in the cross- $\beta$ structure observed by $\mathrm{CD}$ and FT-IR spectra upon fibrillation.

Effect of molecular crowding and possibility of cross-seeding. After addressing the major interactions occurring between proteins and the fibrillation agent, the relevance of molecular crowding in EWP fibrillation was analyzed. Fibrillation experiments with pure ovalbumin, pure lysozyme, and their mixtures were carried out. The concentration of ovalbumin and lysozyme were kept as equivalent to their amount in EWP. Upon addition of [Cho][Tos] at $\mathrm{pH} 2.0$, ovalbumin, lysozyme, and their mixtures show fibrillation as indicated by visual turbidity. These solutions were centrifuged after $24 \mathrm{~h}$ of incubation and the obtained solid samples were redispersed in distilled water. The CD spectra of the 

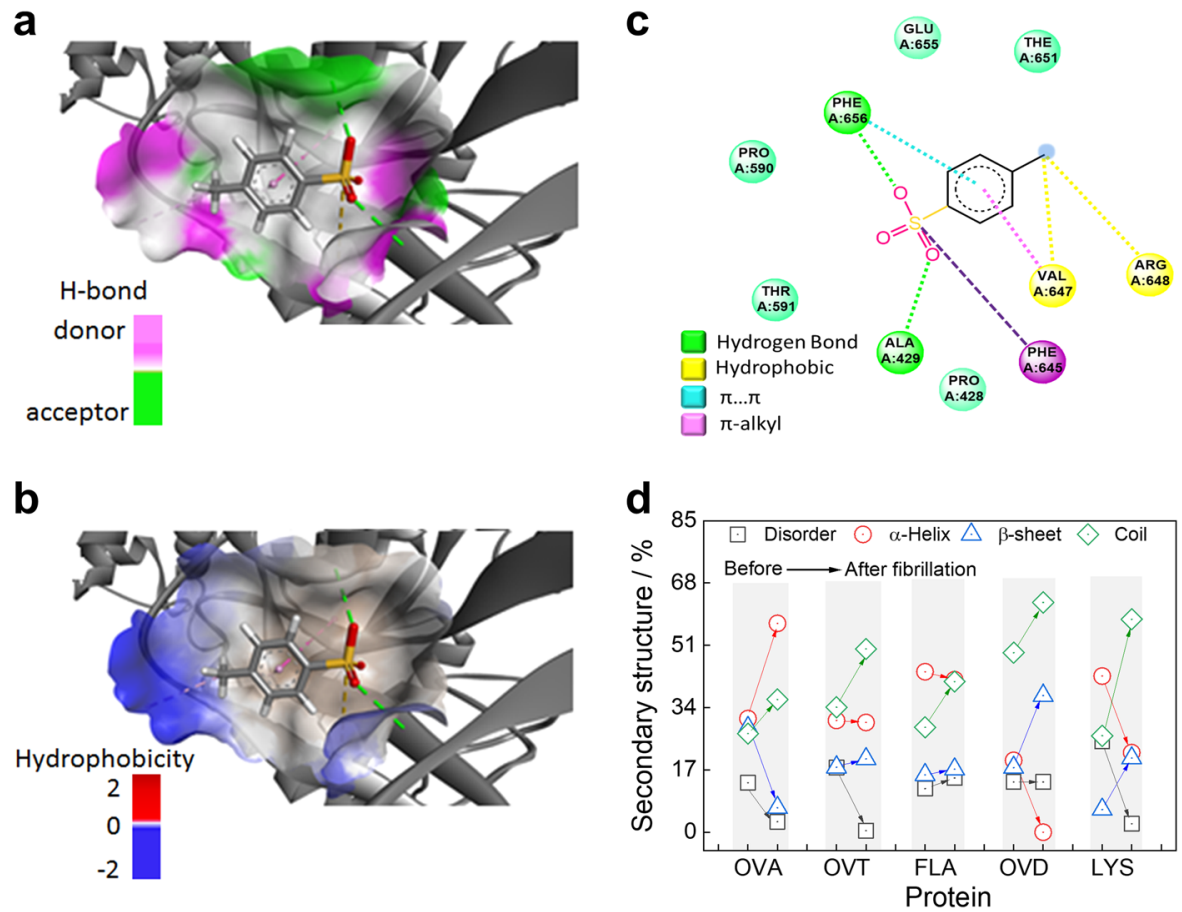

Fig. 5 Molecular docking and PASTA. Snapshots illustrating a hydrogen-bonding ability and $\mathbf{b}$ hydrophobicity of amino acids residues on docking pose with the lowest absolute value of affinity $(\mathrm{kcal} / \mathrm{mol})$ for Ovotransferrin with $[T o s]^{-}$. c Molecular interaction diagrams of [Tos] ${ }^{-}$and amino acids residues of Ovotransferrin. d Changes in the secondary structural conformation of various proteins of EWP: Ovalbumin (OVA), Ovatransferrin (OVT), Flavoprotein (FLA), Ovamucoid (OVD), and Lysozyme (LYS) after fibrillation with [Cho][Tos].

redispersed fibrils show the proteins conformational transition to cross- $\beta$ type secondary structure only for ovalbumin and ovalbumin/lysozyme mixtures, and not for pure lysozyme (Supplementary Fig. 36a-c). These results demonstrate that [Cho][Tos] just forms a charged complex with lysozyme at $\mathrm{pH} 2.0$, which is dissolved upon going back to $\mathrm{pH}$ 7.0.

To confirm whether the lysozyme participates in the fibrillation in the ovalbumin/lysozyme mixture we further analyzed the CD spectra of the supernatants of all samples. The lysozyme supernatant spectrum reveals the presence of proteins with a disordered structure. For pure ovalbumin and the mixture of two proteins, there are evidences for $\alpha+\beta$ conformational state, indicating that proteins are on their way to cross- $\beta$ conformation. These CD spectra, together with the SDS-PAGE results of the supernatants (Fig. 4), indicate that although lysozyme does not fibrillate individually, it does when in proteins mixtures. It should be however highlighted that the cross- $\beta$ structure of ovalbumin and ovalbumin/lysozyme mixture is not as organized as in EWP (Supplementary Fig. 36d). These observations demonstrate the role played by molecular crowding in the fibrillation process via cross seeding.

We further confirmed the previous observations by ThT assays of individual proteins and ovalbumin/lysozyme mixture, whose results are given in Fig. $3 \mathrm{~b}$ and Supplementary Figs. 5 and 6. When moving from a single protein (ovalbumin) to the molecularly crowded EWP proteome, kinetics curves change drastically. The stationary phase is attained faster in EWP with lower fluorescence intensity of ThT as compared to the individual protein assays. Although we cannot assure that cross-seeding is happening in EWP with the accommodation of all proteins into a single fibril, the ThT binding results (Fig. $3 \mathrm{~b}$ ) seem to support this possibility.

The phenomenon of cross seeding of misfolded proteins of different kinds, mainly focused on neurodegenerative diseases, has been previously reported ${ }^{50-56}$. In these studies it has been concluded that cross-seeding is directly proportional to the sequence homology of misfolded intermediates; however, proteins with heterogenous sequences also aggregate together ${ }^{50}$. Juhl et al. $^{53}$ studied the co-aggregation of plasma and cerebrospinal proteins in presence of preformed amyloid fibrils, concluding that fibrils with diverse primary sequences and ultrastructural morphologies only differ slightly in the composition of the coaggregated proteins, whereas exposure to a fibril surface can push aggregation-prone proteins to accumulate. The behavior of our ThT binding curves shown in Fig. $3 \mathrm{~b}$ is in agreement with these results. When moving from an individual protein fibril to EWP fibrils containing proteins of heterogenous sequences, the ThT fluorescence intensity decreases, indicating diverse primary sequences in EWP fibrils with specific monomer packing compared to ovalbumin fibrils ${ }^{53}$.

Other proteins show significant co- and self-aggregation tendency in the crowded medium, as appraised by the data shown in Supplementary Tables 6 and 7. This phenomenon is supported by the beginning of co-/self-aggregation of different proteins from the EWP in the absence of IL as a fibrillation agent, occurring yet after three days as evidenced from the CD spectra of aggregates shown in Fig. 6a.

The overall picture of the possible molecular-level mechanism behind fibrils formation is summarized in Fig. 6, highlighting the essential role of protein crowding in balancing various interactions among the side chains of different proteins (cross seeding) for efficient and fast fibrillation directly from the EWP, which occurs at room temperature in presence of a suitable fibrillation agent such as [Cho][Tos].

Thermal and mechanical properties. The thermal and mechanical properties of the obtained protein fibrils were determined by TGA and DMA. TGA profiles shown in Supplementary Fig. 37a reveal a high thermal stability of protein fibrils, with a glass 

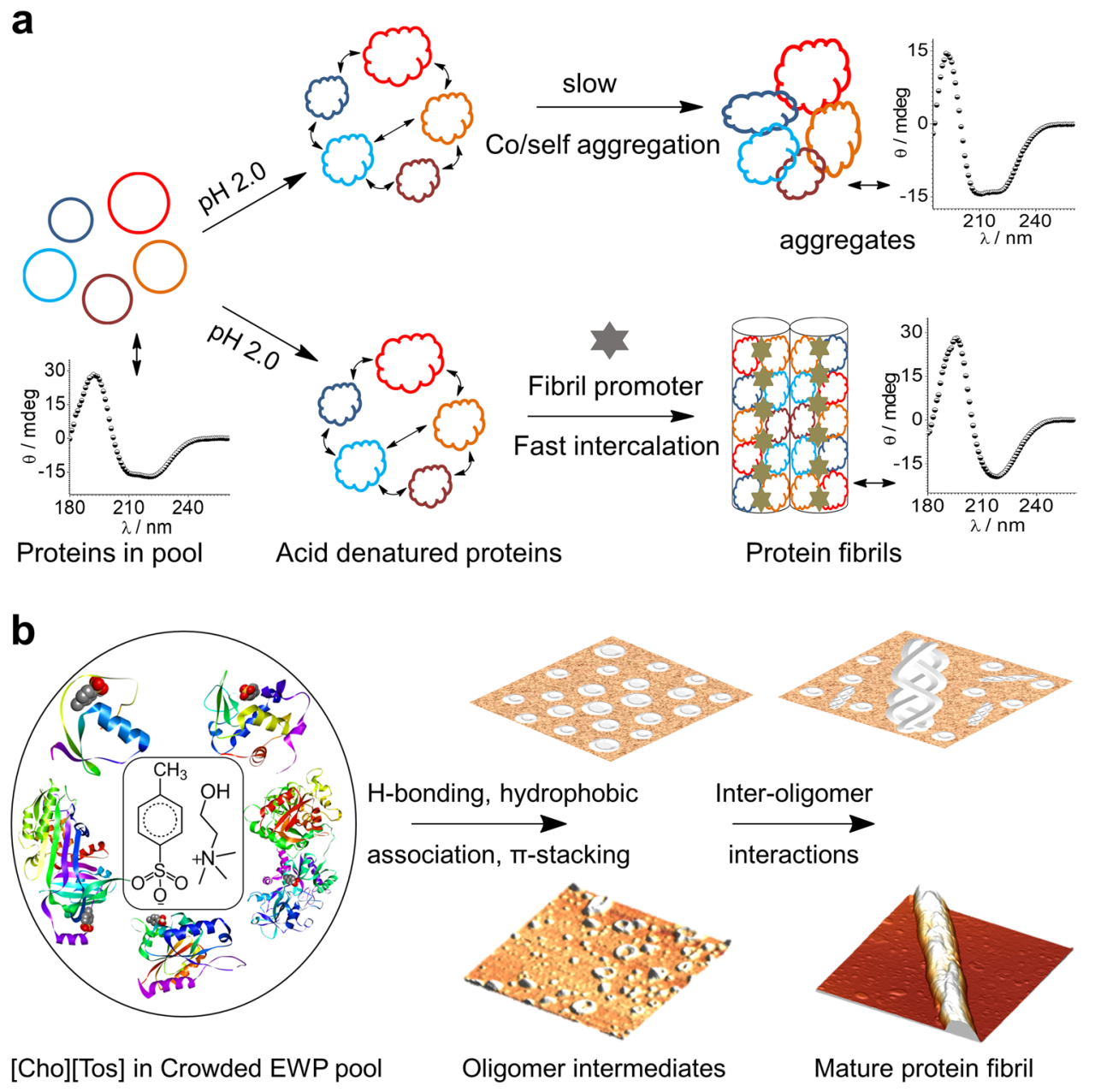

Fig. 6 Schematic overview of the fibrillation mechanism. a Cartoons summarizing the proposed fibrillation mechanism in the egg white proteome with and without the fibrillation agent ([Cho][Tos]) along with the circular dichroism spectra (double sided arrows ( $\leftrightarrow$ ) in the acid denatured proteins indicate the interactions between different proteins). b Schematic representation of the formation of protein fibrils from the egg white proteome using [Cho][Tos], which interacts via hydrogen bonding, hydrophobic, and $\pi$-stacking interactions with different proteins to form oligomer intermediates and protein fibrils.

transition temperature $\left(T_{\mathrm{g}}\right)$ occurring at ca. $95^{\circ} \mathrm{C}$, and thermal degradation temperatures above $307^{\circ} \mathrm{C}$, being comparable with that of amyloid fibrils formed by single proteins ${ }^{57}$ or peptides ${ }^{58}$. The stiffness of the fibrils corresponds to a 2-order of magnitude difference in bulk $\left(E^{\prime}\right)$ and loss modulus $\left(E^{\prime \prime}\right)$ at $25^{\circ} \mathrm{C}$ (Supplementary Fig. $37 \mathrm{~b})^{59}$. A high value of $E^{\prime}(42 \mathrm{GPa})$ was obtained for the fibrils at $25^{\circ} \mathrm{C}$, revealing high stiffness. This value is significantly higher than that obtained for fibrils prepared from $\beta$-casein $(4 \mathrm{GPa})^{38}$ and stacked $\beta$-sheet amyloid of other proteins $(0.67-5 \mathrm{GPa})^{59}$, and comparable with typical A $\beta 40$ amyloid fibril (4.5-54.3 GPa) with varying monomers units ${ }^{60}$. The fibrils strength usually depends on the packing density of the side chains of neighboring $\beta$-sheet, whereas the lack of significant side chains in a protein can give rise to nano-mechanical traits which are potential low mechanical junctions ${ }^{59}$. The proteome heterogeneity in the EWP avoids such junctions, resulting in a better intercalation of fibrils with better packing density and higher mechanical strength. The decrease in $E^{\prime}$ with an increase in temperature occurs due to the fact that different chains of fibrils begin to move freely under thermal motions, causing voids in the fibril matrix.

We also analyzed the mechanical loss factor or damping parameter, $\tan \delta$ (the ratio of loss and bulk modulus), of the prepared fibrils. Changes in temperature reveal the transition between glassy and rubbery regions of materials from two sides of the maxima in a curve $e^{59}$. The prepared fibrils display two maxima of low and high magnitude in the $\tan \delta$ vs. temperature profile, as shown in Supplementary Fig. 37c. The first low magnitude maximum occurring at ca. $80^{\circ} \mathrm{C}$ might not be a true glassyrubbery transition, but rather a relaxation of the cooperative motions of cross-linked chains due to elastic deformations. The second maximum observed at around $170^{\circ} \mathrm{C}$ indicates a true glassy-rubbery transition. Furthermore, it should be remarked that the overall magnitude of $\tan \delta$ is low, suggesting an improved interfacial adhesion which is further reflected in the fibrils high mechanical strength.

The nature of the prepared fibrils was further addressed by zeta potential $(\zeta)$ after dispersing them in water at various $\mathrm{pH}$ values, ranging from 2.0 to 12.0, whose results are given in Supplementary Figs. 38 and 39. The prepared fibrils have enhanced colloidal stability and charge tunable nature, with their zeta potential values varying from $+31 \mathrm{mV}$ at $\mathrm{pH} 2.0$ to $-21 \mathrm{mV}$ at $\mathrm{pH} 10.0$. Taking into account their colloidal stability and charged nature they could be applied as dispersants 61,62 , in biotechnology applications $^{63,64}$ and in biocatalysis ${ }^{65-67}$.

Cytocompatibility. The cytocompatibility of the prepared fibrils was assessed by appraising the viability of the mouse fibroblast L929 cell line via Live-Dead assays, metabolic activity and morphology upon incubation with fibrils (Fig. 7). No impair in cellular membrane integrity (Fig. 7a, b) and morphology (Fig. 7c-f) 
a

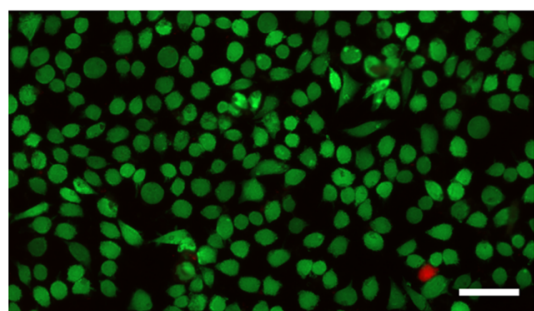

b

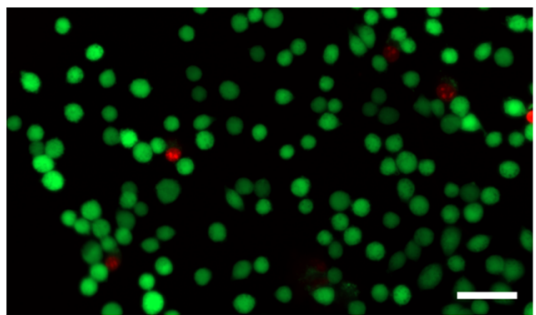

e

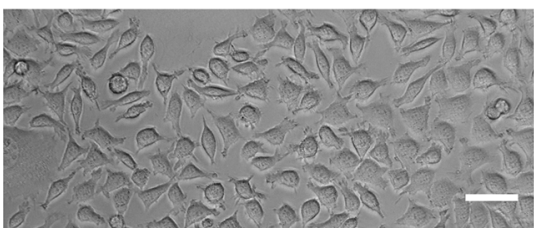

$\mathbf{f}$

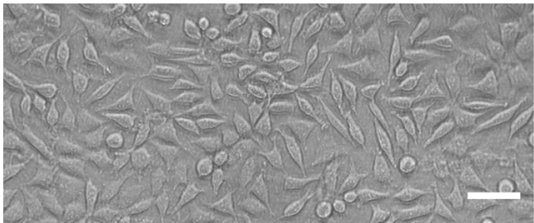

C

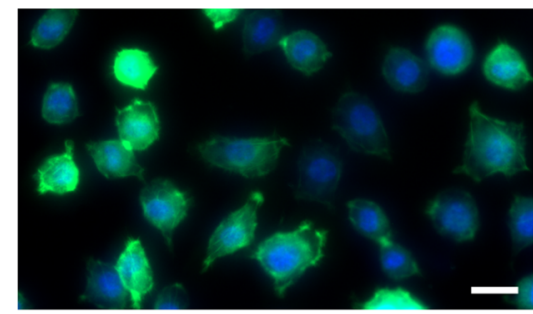

d

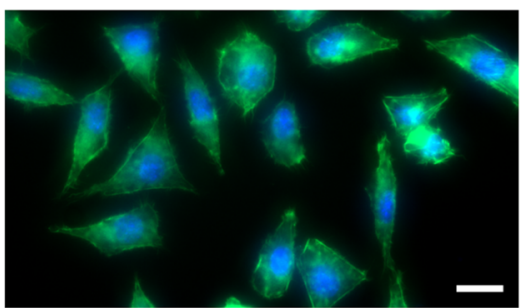

g

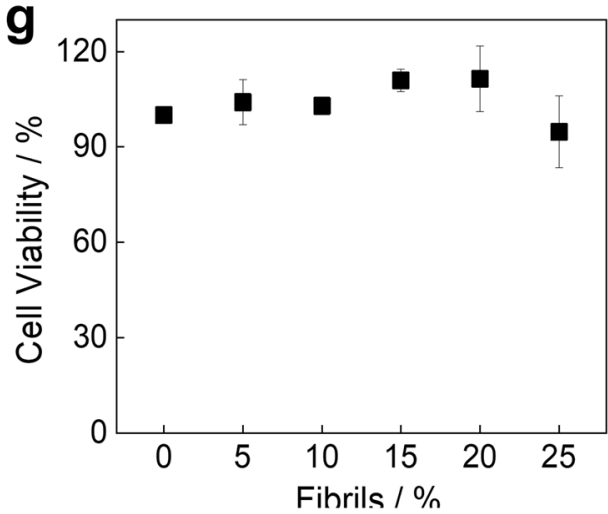

Fig. 7 Cytocompatibility assays of protein fibrils. Live-Dead assay of a control cells and $\mathbf{b}$ in presence of $25 \%$ of protein fibrils (scale bar: $50 \mu \mathrm{m}$ ). Green channel: live cells-Calcein-AM, Red channel: necrotic cells-PI. Fluorescent micrographs of the morphology of $\mathbf{c}$ control cells and $\mathbf{d}$ cells incubated with $25 \%$ of protein fibrils (scale bar: $20 \mu \mathrm{m}$ ). Green channel: F-actin-fluorescein phalloidin, Blue channel: nucleus-DAPI. Optical micrographs of e control cells with no fibrils and $\mathbf{f}$ with cells incubated with $25 \%$ of the EWP fibrils stock solution (scale bar: $50 \mu \mathrm{m}$ ). $\mathbf{g}$ Viability plot of L929 cells in presence of different concentrations of protein fibrils (5-25\%). Data are presented as average \pm standard deviation (NS = no significant difference compared to the control (no fibrils).

was observed after $24 \mathrm{~h}$ in presence of up to $25 \%$ of protein fibrils, supporting their cytocompatibility (uncropped images are shown in Supplementary Fig. 40). The wide-fluorescent images of the Live-Dead assay in the presence of 15 and $20 \%$ fibrils are shown in Supplementary Fig. 41.

The green channels depicted in Fig. 7a, b show the cells stained with Calcein-AM, indicating a viable plasma membrane integrity, whereas the red channels are indicative of dead cell which could not be stained with Calcein-AM due to the membrane rupture. The cytocompatibility of fibrils toward L929 cells was further ascertained by analyzing the cells morphology by the f-actin and nucleus staining (Fig. 7c, d, Supplementary Fig. 42) and optical microscopy (Fig. 7e, f). Cells do not show changes in morphology in the prepared protein fibrils solutions (up to 25\%), reinforcing the fibrils cytocompatibility. The ability of live cells to reduce bluish resazurin to a pinkish highly fluorescent resorufin molecule demonstrates that $\sim 100 \%$ of viable cells exist after the incubation with $5-25 \%$ of protein fibrils (Fig. $7 \mathrm{~g}$ ). A slight decrease in viability of $\sim 6 \%$ ( $94 \%$ viable cells) was observed with $25 \%$ of protein fibrils, being however negligible (Fig. $7 \mathrm{~g}$ ). The cytocompatibility of the prepared fibrils, and among other applications, may open the path to their application as low-cost and bio-based materials for natural extracellular matrix for 3-D cell culture and regenerative medicine ${ }^{68,69}$.
Immobilization of cytochrome $\mathrm{c}$ on protein fibrils. Enzymes immobilization is among the most relevant biotechnological applications of protein fibrils, allowing an easy separation of products from the insoluble fibrils with the attached biocatalyst that can be recycled ${ }^{65,66}$. As a proof of concept on the possible applications of the prepared protein fibrils, we studied the ability of the fibrils to immobilize Cytochrome c (Cyt c) and evaluated their impact upon its activity (Fig. 8). Overall, EWP fibrils display a good tendency to attach Cyt c $(25.7 \mu \mathrm{g} / 14 \mathrm{mg})$. The enzyme immobilization was confirmed by comparative AFM images of fibrils without and with Cyt c, as shown in Fig. 8a, b. Since Cyt c is an oxidoreductase enzyme we analyzed the change in its oxidation state by UV-vis spectra, whose results are depicted in Fig. 8c. The activity assays results using ABTS as substrate in presence of $\mathrm{H}_{2} \mathrm{O}_{2}$ are given in Fig. 8d.

Fibrils cause the reduction of Cyt $\mathrm{c}$, from ferri-Cyt $\mathrm{c}\left(\mathrm{Fe}^{3+}\right)$ to ferro-Cyt $\mathrm{c}\left(\mathrm{Fe}^{2+}\right)$, as indicated by the increase in the absorbance of the peak at $550 \mathrm{~nm}$ and color shift from brown to pinkorange ${ }^{67}$. The activity of immobilized Cyt $\mathrm{c}$ in the fibrils is 2.4537 units $\mu \mathrm{mol} \mathrm{E}^{-1}$, which is 2.5 -fold higher than that observed in water $\left(0.976\right.$ units $\left.\mu \mathrm{mol} \mathrm{E}^{-1}\right)$. Therefore, the fibrils act not only as a support but also allow increasing the activity of Cyt c, revealing their beneficial role in biotechnological applications. Although only one example of application is shown, the low-cost protein 
a

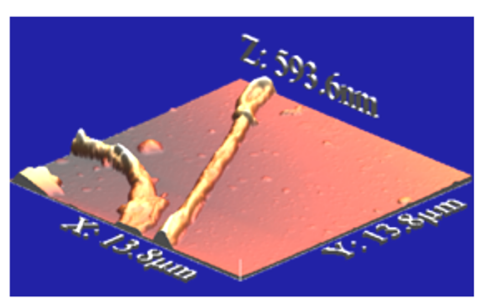

C

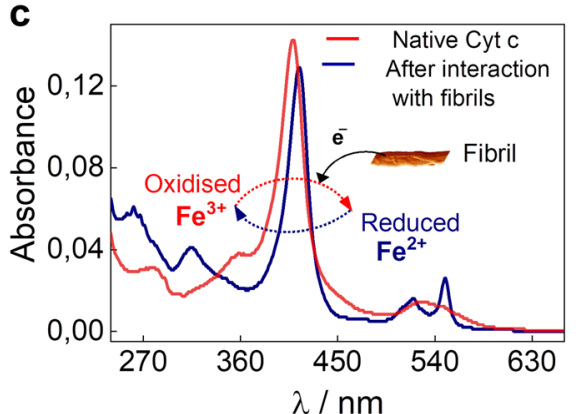

b

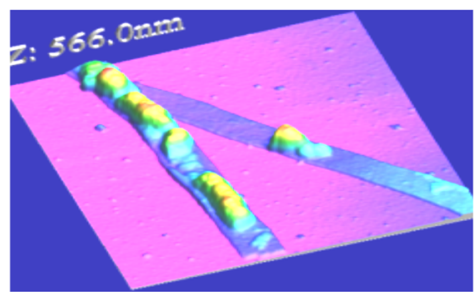

d

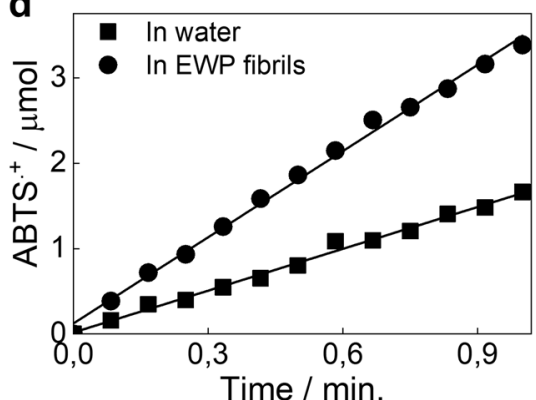

Fig. 8 Enzyme immobilization and activity assay. 3-D AFM images of EWP fibrils a without Cyt $c$ and $\mathbf{b}$ with Cyt $c$ attached to EWP fibrils. $\mathbf{c}$ UV-vis spectra of $\mathrm{Cyt} \mathrm{c}$ before and after immobilization with fibrils. $\mathbf{d}$ Comparative activity of Cyt $\mathrm{c}$ in water and protein fibrils solution according to the formation of $\mathrm{ABTS} \bullet+$ with time upon oxidation of $\mathrm{ABTS}$ as substrate.

fibrils here prepared can be used as smart and/or functional materials in a plethora of nano/biotechnology applications ${ }^{4-7}$.

In summary, we report instantaneous (within seconds) preparation of proteins fibrils directly from a low-cost matrix, namely EW, driven by an IL that acts as a fibrillation agent and heterogenous molecular crowding. By experimental and computational studies, it was found that $\mathrm{H}$-bonding and hydrophobic interactions occurring between the IL and proteins are the driving forces to induce fibrillation, with additional beneficial effects afforded by ILs with aromatic anions by allowing the establishment of $\pi \cdots \pi$ interactions. The obtained fibrils have high mechanical stiffness and are cytocompatible. A case study on their application was shown, namely by acting as enzymes supports and where an enhancement in the activity of Cyt $c$ was found. In summary, a cost-effective strategy to prepare protein fibrils is here reported, where $2 \mathrm{~g}$ of protein fibrils could be prepared from a single egg for less than $5 €$, i.e., at a cost of $2.5 €$ per $\mathrm{g}$ of protein fibrils (cf. Supplementary note 3). These values were obtained at a lab-scale, being estimated that significantly higher amounts of proteins fibrils per batch at a lower cost can be obtained by addressing and optimizing the process scale-up. The low-cost protein fibrils here prepared can open the path to their large-scale application as smart and/or functional materials in a wide range of nano/biotechnology applications.

\section{Methods}

Materials. Chicken eggs were purchased in a local supermarket. Bovine serum albumin (fatty acid free) was purchased from Fischer Scientific. Lysozyme from chicken EW and cytochrome $c$ from equine heart $(>95 \%)$ were acquired from Sigma Aldrich. Cholinium bicarbonate ( $80 \%$ in water with purity $>98 \%$ ), ptoluenesulfonic acid monohydrate $(>98.5 \%)$, methanesulfonic acid $(\geq 99.0 \%)$, benzyldimethyl-(2-hydroxyethyl)ammonium chloride $(>97 \%)$, and cholinium chloride $(98 \%)$ were purchased from Sigma Aldrich. Cholinium tosylate and cholinium methanesulfonate were synthesized by us using an acid base reaction as described elsewhere ${ }^{70}$. The synthesized ILs were dried for $24 \mathrm{~h}$ under high vacuum at $70{ }^{\circ} \mathrm{C}$ for $48 \mathrm{~h}$. A white solid was obtained for cholinium tosylate and a viscous liquid was obtained for cholinium methanesulfonate, which were collected and stored in a vacuum desiccator. The purity of these ILs was confirmed by ${ }^{1} \mathrm{H}$ and ${ }^{13} \mathrm{C}$ NMR and elemental analysis, and found to be $>98 \%$. Thioflavin $\mathrm{T}(>99 \%)$ was purchased from ACROS Organics. Concentrated hydrochloric acid (37\%) was purchased from Sigma Aldrich. All the cell culture media and supplements, namely GIBCO $^{\circledR}$ Dulbecco’s phosphate buffered saline (DPBS), fetal bovine serum (FBS; E. U. approved, South America origin), Dulbecco's modified Eagle's medium low glucose (DMEM-low Glc), TrypLETM Express, and GIBCO ${ }^{\circledast}$ antibiotic/antimycotic solution (ATB) containing 10,000 units/mL of penicillin and $10,000 \mathrm{mg} /$ $\mathrm{mL}$ of streptomycin were purchased from ThermoFisher Scientific (Alfagene, PT). Adherent 96-well plates were purchased from In VitroCell (Sarstedt, PT), nontreated clear bottom 96-well black plates from Corning (Corning, USA) and $13 \mathrm{~mm}$ round-treated coverslip from Sarstedt (Sarstedt, PT). Calcein-AM, Propidium Iodide (PI), DAPI, and fluorescein phalloidin were acquired from Thermo Fisher Scientific Inc (Alfagene, PT).

Microscopy. Optical microscopic images of protein fibrils, at $\times 5$ magnification, were acquired using an Olympus BX51 light polarized microscope (Olympus Co., Tokyo, Japan). Optical microscopic images of cells were acquired using an inverted microscope (Zeiss Primovert, Carl Zeiss, Germany), equipped with PlanACHROMAT $\times 20 / 0.30$. All images were acquired and processed with the Zeiss Zen SP2 Software (Carl Zeiss, Germany). Atomic Force Microscopy (AFM) imaging was performed using the Veeco AFM Multimode Nanoscope (IV) MMAFM-2, USA, in semi contact mode. Samples were prepared by placing a drop of fibrils samples on a mica sheet and dried overnight. Transmission electron microscopy (TEM) images were acquired using a Hitachi H-9000 microscope operating at $300 \mathrm{kV}$. An aliquot of an aqueous dispersion of the protein fibrils was deposited onto a carbon-coated copper grid and the solvent was allowed to evaporate. Fluorescence micrographs were acquired in an upright Widefield fluorescence microscope (Zeiss Imager M2, Carl Zeiss, Germany), equipped with an EC Plan-Neofluar $\times 20 / 0.16$ objective lens and a 3MPix monochromatic camera. All micrographs were acquired and processed in the Zeiss Zen SP2 Software (Carl Zeiss, Germany).

Thermogravimetric analysis (TGA). TGA assays were carried out with a Setsys Evolution 1750 in TGA mode (sensor type S) from Setaram. Samples were heated at a rate of $10^{\circ} \mathrm{C} \mathrm{min}^{-1}$ from 25 to $800^{\circ} \mathrm{C}$, under a $20 \mathrm{~mL} \mathrm{~min}^{-1} \mathrm{~N}_{2}$ flow.

Dynamic mechanical analysis (DMA). DMA measurements were performed on a Tritec 2000 DMA Triton Technologies equipment operating in a single cantilever bending mode. Analyses were performed in the temperature range from 20 to $200{ }^{\circ} \mathrm{C}$ ( $3^{\circ} \mathrm{C}$ step) at 1 and $10 \mathrm{~Hz}$, with the displacement amplitude set to $0.020 \mathrm{~mm}$.

Thioflavin T (ThT) assays. Photoluminescence spectra of thioflavin $\mathrm{T}$ in the visible region were recorded at room temperature with a modular double grating excitation spectrofluorimeter with a TRIAX 320 emission monochromator (Fluorolog-3, Horiba Scientific) coupled to a R928 Hamamatsu photomultiplier, using a right angle acquisition mode. For the ThT assays, $30 \mu \mathrm{M}$ ThT was dissolved in $0.5 \mathrm{~mL}$ EWP at $\mathrm{pH} 2.0$ in a $700 \mu \mathrm{L}$ quartz cell. The spectrum of this sample was acquired after the addition of $50 \mu \mathrm{L}$ of $0.1 \mathrm{M}$ [Cho][Tos]. For ovalbumin and ovalbumin/lysozyme mixture, $30 \mu \mathrm{M}$ ThT was dissolved in $0.5 \mathrm{~mL}$ of their aqueous solutions at $\mathrm{pH} 2.0$, followed by resting for $30 \mathrm{~min}$ and addition of $50 \mu \mathrm{L}$ of $0.1 \mathrm{M}$ [Cho][Tos]. Fluorescence spectra were recorded of each sample for a period of $7.1 \mathrm{~h}$. The excitation source was a $450 \mathrm{~W}$ Xe arc lamp. The emission spectra were 
corrected for detection and optical spectral response of the spectrofluorimeter and the excitation spectra were corrected for the spectral distribution of the lamp intensity using a photodiode reference detector. The emission spectra were monitored at $482 \mathrm{~nm}$ under the excitation at $412 \mathrm{~nm}$. Excitation slit width was $1 \mathrm{~nm}$ and emission slit width was 0.8 .

Circular dichroism (CD). CD spectra were recorded using a Jasco J-815 CD spectrometer at $298.15 \mathrm{~K}$ in the far UV region $(\lambda=180-260 \mathrm{~nm})$. Spectra were collected in a $0.1 \mathrm{~cm}$ path length quartz cuvette at a scan rate of $50 \mathrm{~nm} \mathrm{~min}^{-1}$ and sensitivity of $100 \mathrm{mdeg}$. The response time and the bandwidth were $2 \mathrm{~s}$ and $0.5 \mathrm{~nm}$, respectively. The fibrils were dispersed in distilled water via sonication until a turbid solution was formed. The turbid solution was further diluted to 1:10 (v:v) to record the spectra with the HTV value below 600 which marks the accuracy of the $\mathrm{CD}$ spectrum. The supernatants spectra were recorded in a similar way.

Fourier transform infrared (FT-IR). FT-IR spectra were recorded using a Perkin Elmer Spectrum Bx spectrophotometer in the wavelength range from 1800 to $1300 \mathrm{~cm}^{-1}$. For each spectrum 64 scans were carried out at a resolution of $2 \mathrm{~cm}^{-1}$. The secondary structural analysis was done in the amide I region $\left(1600-1700 \mathrm{~cm}^{-1}\right)$ by a deconvolution method, using the Origin 8.5 software in the wavelength range of $1590-1710 \mathrm{~cm}^{-1}$. Prior to deconvolution, the spectra were smoothed in five points of window using the SavitzkyGolay method in second polynomial order and normalized. The fitting of spectra at $\mathrm{pH} 2.0$ corresponded to $R^{2}=0.997$ and $\chi^{2}=0.00038$ and that of fibrils corresponded to $R^{2}=0.999$ and $\chi^{2}=0.00011$, validating the curve fitting upon deconvolution.

UV-vis spectroscopy. UV-visible spectra of the protein fibrils solution were acquired using an UV-1800 SHIMADZU UV-spectrophotometer in a quartz cuvette of $1 \mathrm{~cm}$ path length. The spectra of Cytochrome $\mathrm{c}$ were measured in quartz cuvette of path length $0.1 \mathrm{~cm}$.

Fluorescence spectroscopy. Fluorescence intensity of the alamarBlue ${ }^{\circledast}$ assays were acquired in a multimode microplate reader (Synergy HTX), equipped with a tungsten halogen lamp and a PMT detector. Intensities were acquired from the bottom of the well plate by filter-based fluorescence optics (excitation wavelength: 540/35 nm; Emission wavelength: 600/40) and processed in the Gen5TM software.

Zeta potential. The Zeta potential was determined using a Zetasizer Nano ZS light scattering apparatus (Malvern Instruments, UK) with a He-Ne laser $(633 \mathrm{~nm}$, $4 \mathrm{~mW}$ ). The fibrils were dispersed in aqueous solutions by adding $4.4 \mathrm{mg}$ of lyophilized fibrils at different $\mathrm{pH}$ values after sonication.

\section{Sodium dodecylsulphate polyacrylamide gel electrophoresis (SDS-PAGE).}

Samples of the supernatants of the aqueous solutions containing fibrils were diluted at $1: 1$ (v:v) in a dissociation buffer consisting of $2.5 \mathrm{~mL}$ of $0.5 \mathrm{M}$ Tris- $\mathrm{HCl} \mathrm{pH} 6.8,4.0 \mathrm{~mL}$ of $10 \%(\mathrm{w} / \mathrm{v})$ SDS solution, $2.0 \mathrm{~mL}$ of glycerol, $2.0 \mathrm{mg}$ of bromophenol blue and $310 \mathrm{mg}$ of dithiothreitol (DTT). This solution was heated at $95^{\circ} \mathrm{C}$ for $5 \mathrm{~min}$ to denature the proteins by reducing disulfide linkages, and thus overcoming some forms of the tertiary protein folding and breaking up the quaternary protein structure. Electrophoresis was run on polyacrylamide gels (stacking: $4 \%$ and resolving: $20 \%$ ) with a running buffer constituted by $250 \mathrm{mM}$ Tris-HCl, $1.92 \mathrm{M}$ glycine, and $1 \% \mathrm{SDS}$. The proteins were stained with Coomassie Brilliant Blue G-250 0.1\% (w/v), methanol 50\% $(\mathrm{v} / \mathrm{v})$, acetic acid $7 \%(\mathrm{v} / \mathrm{v})$, and water $42.9 \%(\mathrm{v} / \mathrm{v})$. All gels were placed overnight in an orbital shaker at a moderate speed at room temperature. Gels were distained in a solution containing acetic acid at $7 \%(\mathrm{v} / \mathrm{v})$, methanol at $20 \%(\mathrm{v} / \mathrm{v})$ and water at $73 \%$ $(\mathrm{v} / \mathrm{v})$ in an orbital shaker at a moderate speed during $3-4 \mathrm{~h}$ at $40^{\circ} \mathrm{C}$. SDS-PAGE Molecular Weight Standards, namely marker molecular weight full-range from VWR, were used as protein standards. Gels were analyzed by taking digital snapshots.

Cytochrome $\mathbf{c}$ assays. The activity of cytochrome $\mathrm{c}$ was measured using ABTS as substrate in presence of $\mathrm{H}_{2} \mathrm{O}_{2}$. The conversion of ABTS to ABTS ${ }^{+}+$upon oxidation was monitored at $420 \mathrm{~nm}$. For native Cyt $\mathrm{c}$ the typical reaction mixture contained $5 \mathrm{mM}$ of ABTS $+1.7 \mu \mathrm{M}$ of Cyt c $+1.66 \mathrm{mM}$ of $\mathrm{H}_{2} \mathrm{O}_{2}$. The reaction was initiated with the addition of $\mathrm{H}_{2} \mathrm{O}_{2}$. The reaction was subjected to 1 min of incubation with the continuous acquisition of the absorbance data at $420 \mathrm{~nm}$. For the activity assays of Cytochrome c supported in the fibrils, $0.014 \mathrm{~g}$ of fibrils were dipped in $0.5 \mathrm{~mL}$ of $12.71 \mu \mathrm{M}$ Cytochrome $\mathrm{c}$ solution for $12 \mathrm{~h}$. The sample was centrifuged at $5000 \mathrm{rpm}$ for $5 \mathrm{~min}$ and the pink orange supernatant (indicating the Cyt $\mathrm{c}$ reduced form) was removed. $25.7 \mu \mathrm{g}$ of Cyt $\mathrm{c}$ was attached to fibrils by centrifugation as detected from UV-vis spectra. The fibrils with attached Cyt $\mathrm{c}$ were then subjected to activity assays. The typical reaction mixture contained $5 \mathrm{mM}$ of ABTS $+1.38 \mu \mathrm{M}$ of Cyt $\mathrm{c}$ $+1.66 \mathrm{mM}$ of $\mathrm{H}_{2} \mathrm{O}_{2}$. The concentrations of both oxidized and reduced Cyt $\mathrm{c}$ were determined by UV-vis spectroscopy.

Cell culture and fibrils incubation. Mouse fibroblasts (L929) cells (European Collection of Authenticated Cell Cultures) were cultured in DMEM-low glucose supplemented with $1 \%$ penicillin/streptomycin and $10 \%$ fetal bovine serum. Cells were maintained in a $\mathrm{CO}_{2}$ incubator at $37^{\circ} \mathrm{C}$ and the medium was replaced every 2 days. One day before each assay, cells were seeded at a density of $1 \times 10^{4}$ and $5 \times$ $10^{4}$ cells/well on a 96-well plates and $13 \mathrm{~mm}$ round-treated coverslips, respectively. Thereafter, the old culture medium was replaced with fresh medium along with the addition of various percentages (25-5\%) of newly prepared EWP fibrils and cells were incubated for $24 \mathrm{~h}$ at $37^{\circ} \mathrm{C}$.

Cell viability and morphology assays. Cell viability was determined by alamarBlue $^{\circledast}$ (ThermoFisher Scientific, USA) and Live-Dead assays. The alamarBlue ${ }^{\circledast}$ assay was performed according to the manufacturer's guidelines. Briefly, $10 \%$ of alamarBlue $^{\circledast}$ buffer was added to each well and the incubation was continued for $3 \mathrm{~h}$. Afterwards, aliquots of $100 \mu \mathrm{L}$ were taken from each well and transferred to a nontreated 96-well black plates with clear bottom, and the obtained fluorescence intensity was measured by a multimode microplate reader. For the Live-Dead assay, cells seeded on round coverslips were labeled with Calcein-AM $(3 \mu \mathrm{g} / \mathrm{mL})$ and Propidium Iodide (PI) $(6 \mu \mathrm{g} / \mathrm{mL})$ for $30 \mathrm{~min}$ at $37^{\circ} \mathrm{C}$. Following incubation, cells were rinsed with DPBS and immediately observed by upright fluorescence microscopy. Cell morphology was evaluated by F-actin and nucleus staining with phalloidin and DAPI, respectively. To this end, after $24 \mathrm{~h}$ incubation with each concentration of EWP fibrils, cells seeded on round coverslips were fixed with $4 \%$ formaldehyde during $20 \mathrm{~min}$, rinsed with DPBS and incubated with fluorescein phalloidin $(25 \mu \mathrm{g} / \mathrm{mL})$ for $30 \mathrm{~min}$ at $37^{\circ} \mathrm{C}$ followed by DAPI $(1 \mu \mathrm{g} / \mathrm{mL})$ for $5 \mathrm{~min}$. Following incubation, cells were rinsed with DPBS and analyzed by upright fluorescence microscopy.

\section{Data availability}

The original datasets generated and analyzed during the current study are available from the corresponding author on reasonable request.

Received: 7 December 2019; Accepted: 27 April 2020;

Published online: 11 June 2020

\section{References}

1. Soto, C. Unfolding the role of protein misfolding in neurodegenerative diseases. Nat. Rev. Neurosci. 4, 49-60 (2003).

2. Dobson, M. Protein folding and misfolding. Nature 426, 884 (2003).

3. Reynolds, N. P. et al. Competition between crystal and fibril formation in molecular mutations of amyloidogenic peptides. Nat. Commun. 8, 1338-1347 (2017).

4. Knowles, T. P. J., Oppenheim, T. W., Buell, A. K., Chirgadze, D. Y. \& Welland, M. E. Nanostructured films from hierarchical self-assembly of amyloidogenic proteins. Nat. Nanotechnol. 5, 204-207 (2010).

5. Li, C., Adamcik, J. \& Mezzenga, R. Biodegradable nanocomposites of amyloid fibrils and graphene with shape-memory and enzyme-sensing properties. Nat. Nanotechnol. 7, 421-427 (2012).

6. Hauser, C. A. E., Maurer-Strohb, S. \& Martins, I. C. Amyloid-based nanosensors and nanodevices. Chem. Soc. Rev. 43, 5326-5345 (2014).

7. Kapil, N., Singh, A. \& Das, D. Cross- $\beta$ amyloid nanohybrids loaded with cytochromec exhibit superactivity in organic solvents. Angew. Chem. Int. Ed. 54, 6492-6495 (2015)

8. Jonesa, O. G. \& Mezzenga, R. Inhibiting, promoting, and preserving stability of functional protein fibrils. Soft Matter 8, 876-895 (2012).

9. Tyedmers, J., Mogk, A. \& Bukau, B. Cellular strategies for controlling protein aggregation. Nat. Rev. Mol. Cell Biol. 11, 777-788 (2010).

10. Greenwald, J. \& Riek, R. Biology of amyloid: structure, function, and regulation. Structure 18, 1244-1260 (2010).

11. Rambaran, R. N. \& Serpell, L. C. Amyloid fibrils. Prion 2, 112-117 (2008).

12. Tipping, K. W. et al. $\mathrm{pH}$-induced molecular shedding drives the formation of amyloid fibril-derived oligomers. Proc. Natl. Acad. Sci. USA 112, 5691-5696 (2015).

13. Surmacz-Chwedoruk, W., Babenko, V., Dec, R., Szymczak, P. \& Dzwolak, W. The emergence of superstructural order in insulin amyloid fibrils upon multiple rounds of self-seeding. Sci. Rep. 6-32022, 1-12 (2016).

14. Macchi, F., Eisenkol, M., Kiefer, H. \& Otzen, D. E. The effect of osmolytes on protein fibrillation. Int. J. Mol. Sci. 13, 3801-3819 (2012).

15. Kirschner, D. A. et al. Synthetic peptide homologous to $\beta$-protein from Alzheimer disease forms amyloid-like fibrils in vitro. Proc. Natl. Acad. Sci. USA 84, 6953-6957 (1987).

16. Kirschner, D. A. et al. In vitro amyloid fibril formation by synthetic peptides corresponding to the amino terminus of aposaa isoforms from amyloidsusceptible and amyloid-resistant mice. J. Struct. Biol. 124, 88-98 (1998).

17. Lee, J., Culyba, E. K., Powers, E. T. \& Kelly, J. W. Amyloid- $\beta$ forms fibrils by nucleated conformational conversion of oligomers. Nat. Chem. Biol. 7 , 602-609 (2011). 
18. Zapadka, K. L., Becher, F. J., Uddin, S., Varley, P. G. \& Bishop, S. A pHinduced switch in human glucagon-like peptide-1 aggregation kinetics. J. Am. Chem. Soc. 138, 16259-16265 (2016).

19. Bemporad, F., Taddei, N., Stefani, M. \& Chiti, F. Assessing the role of aromatic residues in the amyloid aggregation of human muscle acylphosphatase. Prot. Sci. 15, 862-870 (2006).

20. Porat, Y., Abramowitz, A. \& Gazit, E. Inhibition of amyloid fibril formation by polyphenols: structural similarity and aromatic interactions as a common inhibition mechanism. Chem. Biol. Drug Des. 67, 27-37 (2006).

21. Zanuy, D., Porat, Y., Gazit, E. \& Nussinov, R. Peptide sequence and amyloid formation: molecular simulations and experimental study of a human islet amyloid polypeptide fragment and its analogs. Structure 12, 439-455 (2004).

22. Murugan, E. et al. $\mathrm{pH}$. induced conformational transitions in the transforming growth factor $\beta$-induced protein (TGF $\beta$ Ip) associated corneal dystrophy mutants. Sci. Rep. 6-23836, 1-17 (2016).

23. Juárez, J., Taboada, P. \& Mosquera, V. Existence of different structural intermediates on the fibrillation pathway of human serum albumin. Biophys. J. 96, 2353-2370 (2009).

24. Rogers, R. D. Materials science: reflections on ionic liquids. Nature 447, 917 (2007).

25. Byrne, N., Angell, C. A. Formation and dissolution of hen egg white lysozyme amyloid fibrils in protic ionic liquids. Chem. Commun. 1046-1048 (2009).

26. Kalhor, H. R., Kamizi, M., Akbari, J. \& Heydari, A. Inhibition of amyloid formation by ionic liquids: ionic liquids affecting intermediate oligomers. Biomacromolecules 10, 2468-2475 (2009).

27. Singh, G. \& Kang, T. S. Ionic liquid surfactant mediated structural transitions and self-assembly of bovine serum albumin in aqueous media: effect of functionalization of ionic liquid surfactants. J. Phys. Chem. B 119, 10573-10585 (2015).

28. Ghosh, K., de Graff, A. M. R., Sawle, L. \& Dill, K. A. Role of proteome physical chemistry in cell behavior. J. Phys. Chem. B 120, 9549-9563 (2016)

29. Tan, C., Saurabh, S., Bruchez, M. P., Schwartz, R. \& LeDuc, P. Molecular crowding shapes gene expression in synthetic cellular nanosystems. Nat. Nanotechnol. 8, 602-608 (2013).

30. Kim, Y. C., Best, R. B. \& Mittal, J. Macromolecular crowding effects on protein-protein binding affinity and specificity. J. Chem. Phys. 133, 205101 (2010).

31. Richter, K., Nessling, M. \& Lichter, P. Experimental evidence for the influence of molecular crowding on nuclear architecture. J. Cell Sci. 120, 1673-1680 (2007).

32. Ellis, R. J. \& Minton, A. P. Protein aggregation in crowded environments. Biol. Chem. 387, 485-497 (2006).

33. White, D. A., Buell, A. K., Knowles, T. P. J. \& Welland, M. E. Protein aggregation in crowded environments. J. Am. Chem. Soc. 132, 5170-5175 (2010).

34. Ma, Q. et al. The contrasting effect of macromolecular crowding on amyloid fibril formation. PLoS ONE 7, 1-13 (2012).

35. Mann, K. \& Mann, M. In-depth analysis of the chicken egg white proteome using an LTQ Orbitrap Velos. Proteome Sci. 9, 1-6 (2011).

36. Goto, Y. Optical Modulation: Advanced Techniques and Applications in Transmission. Proc. Symp. Ultra. Electr. 33, 17-18 (2012).

37. Khurana, R. et al. Mechanism of thioflavin T binding to amyloid fibrils. $J$. Struc. Biol. 151, 229-238 (2005).

38. Pan, K. \& Zhong, Q. Amyloid-like fibrils formed from intrinsically disordered caseins: physicochemical and nanomechanical properties. Soft Matter 11, 5898-5904 (2015).

39. Stanyon, H. F. \& Viles, J. H. Human serum albumin can regulate amyloid- $\beta$ peptide fiber growth in the brain interstitium. J. Biol. Chem. 287, 28163-28168 (2012).

40. Nasica-Labouze, J. et al. Amyloid $\beta$ protein and Alzheimer's disease: when computer simulations complement experimental studies. Chem. Rev. 115, 3518-3563 (2015).

41. Anand, B. G., Dubey, K., Shekhawat, D. S. \& Kar, K. Intrinsic property of phenylalanine to trigger protein aggregation and hemolysis has a direct relevance to phenylketonuria. Sci. Rep 7, 11146 (2017). 1-9.

42. Manavalan, P. \& Johnson, W. C. Jr. Sensitivity of circular dichroism to protein tertiary structure class. Nature 305, 831-832 (1983).

43. Ladner-Keay, C. L., Griffith, B. J. \& Wishart, D. S. Shaking alone induces de novo conversion of recombinant prion proteins to $\beta$-Sheet rich oligomers and fibrils. PLoS ONE 9, e98753 (2014). 1-12.

44. Kauppinen, J. K., Moffatt, D. J., Mantsch, H. H. \& Cameron, D. G. Fourier self-deconvolution: a method for resolving intrinsically overlapped bands. Appl. Spectrosc. 35, 271 (1981).

45. Herald, T. J. \& Smith, D. M. J. Heat-induced changes in the secondary structure of hen egg S-ovalbumin. Agric. Food Chem. 40, 1737-1740 (1992).

46. Pivato, M. et al. Covalent $\alpha$-synuclein dimers: chemicophysical and aggregation properties. PLoS ONE 7, 1-12 (2012).
47. Chiti, F. et al. Designing conditions for in vitro formation of amyloid protofilaments and fibrils. Proc. Natl. Acad. Sci. USA 96, 3590-3594 (1999).

48. Prusiner, S. B. Autobiography. NobelPrize.org. Retrieved 2007-01-02.

49. Walsh, I., Seno, F., Tosatto, S. C. E. \& Trovato, A. PASTA 2.0: an improved server for protein aggregation prediction. Nucleic Acids Res. 42, W301-W307 (2014).

50. Morales, R., Moreno-Gonzalez, I. \& Soto, C. Cross-seeding of misfolded proteins: implications for etiology and pathogenesis of protein misfolding diseases. PLoS Pathog. 9, e1003537-e1003537 (2013).

51. Villar, V. A. et al. Molecular and clinical aspects of protein aggregation assays in neurodegenerative diseases. Mol. Neurobiol. 55, 7588-7605 (2018).

52. Surmacz-Chwedoruk, W., Malka, I., Bozycki, Ł., Nieznan'ska, H. \& Dzwolak, W. On the heat stability of amyloid-based biological activity: insights from thermal degradation of insulin fibrils. PLoS ONE 9, e86320 (2014). 1-7.

53. Juhl, D. W. et al. Conservation of the amyloid interactome across diverse fibrillar structures. Sci. Rep. 9, 3863 (2019).

54. O’Nuallain, B., Williams, A. D., Westermark, P. \& Wetzel, R. Seeding specificity in amyloid growth induced by heterologous fibrils. J. Biol. Chem. 279, 17490-17499 (2004).

55. Clinton, L. K., Blurton-Jones, M., Myczek, K., Trojanowski, J. Q. \& LaFerla, F M. Synergistic interactions between Abeta, tau, and alpha-synuclein: acceleration of neuropathology and cognitive decline. J. Neurosci. 30, 7281-7289 (2010)

56. Krebs, M. R., Morozova-Roche, L. A., Daniel, K., Robinson, C. V. \& Dobson, C. M. Observation of sequence specificity in the seeding of protein amyloid fibrils. Protein Sci. 13, 1933-1938 (2004).

57. Adler-Abramovich, L. et al. Thermal and chemical stability of diphenylalanine peptide nanotubes: implications for nanotechnological applications. Langmuir 22, 1313-1320 (2006).

58. Ornaghi, H. L. Jr., Bolner, A. S., Fiorio, R., Zattera, A. J. \& Amico, S. C. Mechanical and dynamic mechanical analysis of hybrid composites molded by resin transfer molding. J. Appl. Polym. Sci. 118, 887-896 (2010).

59. Lamour, G. et al. Mapping the broad structural and mechanical properties of amyloid fibrils. Biophys. J. 112, 584-594 (2017)

60. Paul, T. J. et al. Structural and mechanical properties of amyloid beta fibrils: a combined experimental and theoretical approach. J. Phys. Chem. Lett. 7, 2758-2764 (2016)

61. Peng, J., Simon, J. R., Venema, P. \& Linden, E. V. Stability of colloidal dispersions in the presence of protein fibrils. Soft Matter 12, 3514-3526 (2016).

62. Peng, J., Simon, J. R., Venema, P. \& Linden, E. V. Protein fibrils induce emulsion stabilization. Langmuir 32, 2164-2174 (2016).

63. Zhang, S. Fabrication of novel biomaterials through molecular self-assembly. Nat. Biotechnol. 21, 1171-1178 (2003).

64. Jung, J. P., Gasiorowski, J. Z. \& Collier, J. H. Fibrillar peptide gels in biotechnology and biomedicine. Biopolymers 94, 49-59 (2010).

65. Bharmoria, P., Trivedi, T. J., Samanta, A. \& Kumar, A. Ionic liquid-induced all- $\alpha$ to $\alpha+\beta$ conformational transition in cytochrome $c$ with improved peroxidase activity in aqueous medium. Phys. Chem. Chem. Phys. 17, 10189-10199 (2015)

66. Spinazzi, M., Casarin, A., Pertegato, V., Salviati, L. \& Angelini, C. Assessment of mitochondrial respiratory chain enzymatic activities on tissues and cultured cells. Nat. Protoc. 7, 1235-1246 (2012).

67. Polizzi, K. M., Bommarius, A. S., Broering, J. M. \& Chaparro-Riggers, J. F. Stability of biocatalysts. Curr. Opin. Chem. Biol. 11, 220-225 (2007).

68. Shimanovich, U. et al. Protein microgels from amyloid fibril networks. ACS Nano 9, 43-51 (2015)

69. Silva, G. A. et al. Selective differentiation of neural progenitor cells by highepitope density nanofibers. Science. 303, 1352-1355 (2007).

70. Mukesh, C., Mondal, D., Sharma, M. \& Prasad, K. Rapid dissolution of DNAin a novel bio-based ionic liquid with long-term structural and chemicalstability: successful recycling of the ionic liquid for reuse in the process. Chem. Commun. 49, 6849-6851 (2013).

\section{Acknowledgements}

This work was developed within the scope of the project CICECO-Aveiro Institute of Materials, UIDB/50011/2020 \& UIDP/50011/2020, financed by national funds through the Portuguese Foundation for Science and Technology/MCTES. The authors acknowledge the financial support from the European Union Framework Program for Research and Innovation HORIZON 2020, under the TEAMING Grant agreement No. 739572-The Discoveries CTR. M.C.N. acknowledges FCT for the research contract CEECIND/00383/2017 under the CEEC Individual 2017. I. Bdikin acknowledges FCT for the financial support (IF/00582/2015, UID/EMS/00481/2019FCT). M.G. Freire acknowledges the European Research Council under the European Union's Seventh Framework Program (FP7/2007-2013)/ERC grant agreement no. 337753. A.M. Botas from University of Aveiro is acknowledged for the help in the photoluminescence data acquisition. 


\section{Author contributions}

P.B. conceived, designed, and performed the experiments (fibrillation, optical microscopy, FTIR, CD, and zeta potential), interpreted the data and wrote the original version of the paper. D.M. conceived, designed, and performed the experiments (ILs synthesis, mechanical properties, and activity assays) of this work, interpreted the data, and contributed to the paper preparation. M.G.F. conceived and designed the work, interpreted the data, and contributed to the paper preparation. J.A.P.C. interpreted the data and contributed to the paper preparation. M.M.P. performed the computational analysis and wrote the respective part in the paper. M.R.A. performed SDS-PAGE and assisted in the Thioflavin experiments. M.C.N. performed the TEM images acquisition. M.C.G. performed the cell viability assays and wrote the respective part in the paper. J.F.M. interpreted the cell viability data and helped in the writing of the respective part in the paper. I.B. performed the AFM imaging. R.A.S.F. performed the thioflavin experiments and wrote the respective part in the paper.

\section{Competing interests}

The authors declare no competing interests.

\section{Additional information}

Supplementary information is available for this paper at https://doi.org/10.1038/s43246020-0035-0.
Correspondence and requests for materials should be addressed to J.A.P.C. or M.G.F.

Reprints and permission information is available at http://www.nature.com/reprints

Publisher's note Springer Nature remains neutral with regard to jurisdictional claims in published maps and institutional affiliations.

\section{(c) (1)}

Open Access This article is licensed under a Creative Commons Attribution 4.0 International License, which permits use, sharing, adaptation, distribution and reproduction in any medium or format, as long as you give appropriate credit to the original author(s) and the source, provide a link to the Creative Commons license, and indicate if changes were made. The images or other third party material in this article are included in the article's Creative Commons license, unless indicated otherwise in a credit line to the material. If material is not included in the article's Creative Commons license and your intended use is not permitted by statutory regulation or exceeds the permitted use, you will need to obtain permission directly from the copyright holder. To view a copy of this license, visit http://creativecommons.org/ licenses/by/4.0/.

(C) The Author(s) 2020 